\title{
Dose-Dependent Enhancement of Morphine-Induced Analgesia by Ingestion of Amniotic Fluid and Placenta
}

\author{
MARK B. KRISTAL, PATRICIA ABBOTT AND ALEXIS C. THOMPSON \\ Department of Psychology, State University of New York at Buffalo, Buffalo, NY 14260
}

Received 18 December 1987

\begin{abstract}
KRISTAL, M. B., P. ABBOTT AND A. C. THOMPSON. Dose-dependent enhancement of morphine-induced analgesia by ingestion of amniotic fluid and placenta. PHARMACOL BIOCHEM BEHAV 31(2) 351-356, 1988. - Ingestion of amniotic fluid and placenta by rats has been shown to enhance opioid-mediated analgesia. The present studies were designed to examine the effect of several doses and volumes of placenta and amniotic fluid on tail-flick latency in rats treated with $3 \mathrm{mg} / \mathrm{kg}$ morphine. The optimal dose of amniotic fluid was found to be $0.25 \mathrm{ml}$, although 0.50 and $1.0 \mathrm{ml}$ also produced significant enhancement. Doses of 0.125 and $2 \mathrm{ml}$ of amniotic fluid were ineffective, as was a dose of $0.25 \mathrm{ml}$ diluted to $2 \mathrm{ml}$ with saline. The optimal dose of placenta was found to be 1 placenta, although the resulting enhancement was not significantly greater than that produced by $0.25,0.50,2.0$ or 4.0 placentas. Doses smaller than 0.25 placenta or larger than 4.0 placentas were ineffective. The most effective doses of amniotic fluid and placenta correspond to the amounts delivered with each pup during parturition.
\end{abstract}

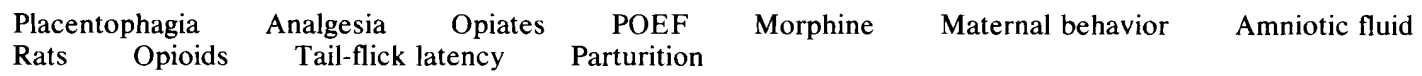

PLACENTA and amniotic fluid have been shown to contain a substance (POEF, for Placental Opioid-Enhancing Factor) that, when ingested, enhances existing opioid-mediated analgesia, as measured by tail-flick latency (TFL) in rats (6-8). Ingestion of these afterbirth substances in the absence of opiate-mediated analgesia, however, does not produce analgesia. This suggests that POEF does not simply increase available opioids, but rather enhances the effect of opioids that are present. Treatment with the opiate-blocker naltrexone not only eliminates the opiate-mediated analgesia that is present, but also renders ingested placenta or amniotic fluid ineffective $(6,7)$.

Ingestion of either placenta or amniotic fluid has been shown to enhance three types of opiate-mediated, or partly opiate-mediated, analgesia: that produced by injection of morphine sulfate $(7,8)$; that produced by footshock $(7)$; and that produced by mechanical vaginal/cervical sitmulation (8). Amniotic fluid shows POEF activity whether eaten or delivered directly to the stomach by orogastric tube (6).

The present studies were designed to examine the dose characteristics of POEF in rats treated with a standard dose of morphine sulfate.

\section{EXPERIMENT 1}

The opiate-analgesia-enhancing effect of five doses of amniotic fluid was examined in rats treated with a threshold dose $(3 \mathrm{mg} / \mathrm{kg}$ ) of morphine sulfate.

METHOD

Subjects

Eighty adult virgin Long-Evans female rats, about 120 days of age, and having a mean weight of $252 \pm 2.1 \mathrm{~g}$, were used. All rats showed normal estrous cyclicity, determined by daily inspection of vaginal smears, and were housed in $24.5 \times 18 \times 18-\mathrm{cm}$ hanging wire-mesh cages in a colony maintained on a $14 \mathrm{hr}$ on $/ 10 \mathrm{hr}$ off light cycle (lights on at 0500 EST). Except where noted, all rats had ab lib access to water and chow (Agway Prolab Rat/Mouse/Hamster Formula 3000 ).

\section{Apparatus}

The "tail-flick" algesiometer used to measure pain thresholds was similar to those used in other laboratories (3, 4,10 ). Heat produced by a $500-\mathrm{W}$ projector lamp (Sylvania DEK-DFW) was beamed through a $1.8-\mathrm{cm}$ aperture at a rat's tail $2 \mathrm{~cm}$ away. When the heat became uncomfortable, the rat moved its tail and the stimulus was terminated. The intensity of the bulb was kept constant as the bulb aged by monitoring the output and increasing the input with a poten- 


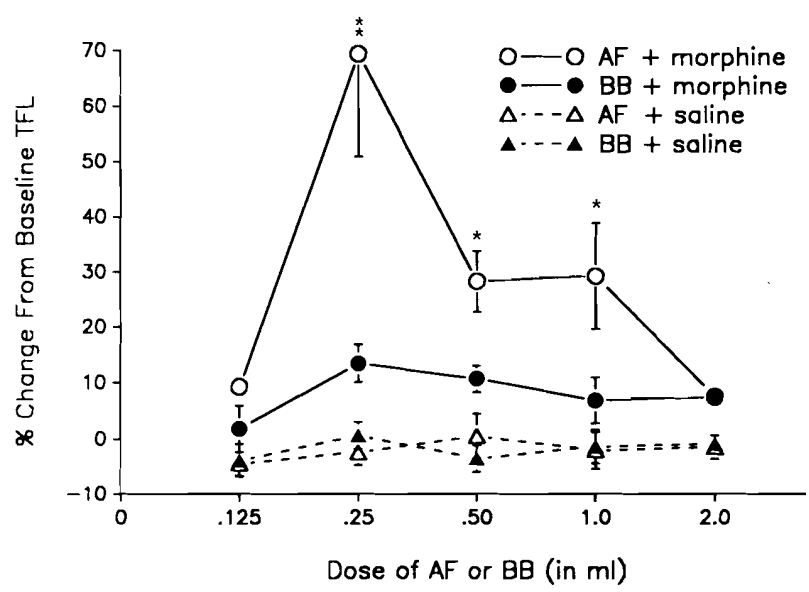

FIG. 1. Mean percent change from baseline tail-flick latency (TFL) in rats infused with various doses of either amniotic fluid (AF) or beef bouillon (BB), and injected with either morphine or saline. (Uninfused rats receiving morphine in this paradigm show the same change in TFL as BB + morphine rats.) ${ }^{* *}$ Significantly different from all other groups; *significantly greater than baseline.

tiometer. The bulb output was initially set below maximum, and was calibrated by having it produce tail-flick latencies of 3-4 sec in normal rats. If no response occurred within $8 \mathrm{sec}$, the stimulus was terminated to avoid tissue damage in rats experiencing analgesia. The dependent variable was the number of seconds that elapsed between the onset of the heat and the movement of the tail (tail-flick latency, or TFL). During the TFL tests, rats were restrained in opaque polyvinyl tubes $(5 \times 21 \mathrm{~cm})$ to which they had previously been habituated. They were allowed to habituate to the restrainer for the $2 \mathrm{~min}$ before the first TFL trial. Each TFL score was the mean of the last three of four TFL trials conducted at 30 -sec intervals.

The experimental and control fluids were administered through an orogastric tube consisting of $11.5-\mathrm{cm}$ length of PE-160 tubing, fitted to a blunted 16-ga hypodermic needle. The needle was mounted on either a $0.25-\mathrm{ml}, 1-\mathrm{ml}$, or a $2-\mathrm{ml}$ syringe. Each rat had been intubated (without infusion of fluid) five times before the first test day.

\section{Procedure}

The overall design of the experiment was a $2 \times 2 \times 5$ factorial: Drug (morphine, saline) $\times$ Fluid (amniotic fluid, beef bouillon) $\times$ Dose of Fluid $(0.125,0.25,0.50,1.00,2.00 \mathrm{ml})$. Each rat was tested twice, once after a morphine injection (morphine sulfate, $3 \mathrm{mg} / \mathrm{kg}$, IP) and once after a vehicle control injection $(0.9 \%$ saline, $1 \mathrm{ml} / \mathrm{kg}$, IP). The two tests occurred two weeks apart and the order was balanced.

Food and water were removed from the home cage $3 \mathrm{hr}$ prior to testing. At the beginning of the test, a baseline TFL measure was taken and the drug injection administered. After $25 \mathrm{~min}$, the rat was intubated and infused with either amniotic fluid or beef bouillon in one of five doses. Twenty minutes later, the postingestion TFL was determined. The percent change from baseline TFL was computed for each rat; the mean percent change from baseline TFL was computed for each group.

Amniotic fluid was obtained from time-bred donors euthanized on Day 21 of pregnancy with $\mathrm{CO}_{2}$. Each fetoplacen- tal unit in its intact amniotic sac was dissected out without delay. A small puncture was made in the amniotic sac and the fluid drained into a glass dish. All the amniotic fluid harvested from one donor was collected in the same dish, transferred to small vials in volumes ranging from 0.125 to $1 \mathrm{ml}$, then immediately frozen. The placentas from these same donors were harvested and stored separately.

For presentation of amniotic fluid to subjects, the small vials of amniotic fluid were rapidly thawed and warmed to $37^{\circ}$ in a heating block.

The control for amniotic fluid was beef bouillon (Wyler's Instant), prepared at half the recommended concentration, then frozen and subsequently treated identically to amniotic fluid (6).

As a check for the effects of morphine only and saline only, five additional rats were treated identically to the others but no fluid was infused during the intubation procedure.

The experimenter testing TFL was always blind to the condition of the rat.

\section{RESULTS AND DISCUSSION}

The results of Experiment 1 are depicted in Fig. 1.

The baseline TFLs did not differ significantly among the groups. They ranged from a mean of $3.13 \pm 0.04 \mathrm{sec}$ in the morphine-injected rats receiving $0.125 \mathrm{ml}$ of amniotic fluid (AF), to a mean of $3.41 \pm 0.08 \mathrm{sec}$ in the saline-injected rats receiving $0.25 \mathrm{ml}$ of beef bouillon $(\mathrm{BB}), \mathrm{F}(19,140)=1.04$, $p>0.05$.

A three-way ANOVA revealed a significant Drug $\times$ Fluid $\times$ Dose of Fluid interaction, $F(4,70)=4.31, p<0.005$. Subsequent two-way ANOVAs probing the various effects revealed a significant Drug $\times$ Dose of Fluid interaction for amniotic fluid, $\mathrm{F}(4,70)=10.90, p<0.0001$; a significant Fluid $\times$ Dose of Fluid interaction for morphine, $F(4,140)=7.14$, $p<0.01$; and a significant Drug $\times$ Fluid interaction for rats receiving either 0.25 or $1.00 \mathrm{ml}$ of fluid, $F(1,70)=30.84$, $p<0.0001$, and $\mathrm{F}(1,70)=4.73, p<0.05$, respectively. More detailed analyses were then conducted using ANOVAs and Newman-Keuls tests.

Morphine-injected (Morph) rats fed $0.25,0.5$, or $1.0 \mathrm{ml}$ of amniotic fluid showed significantly greater increases from baseline (more analgesia) than did the saline-injected controls (Sal) fed the same doses of amniotic fluid: AF $(0.25 \mathrm{ml}) /$ Morph vs. AF $(0.25 \mathrm{ml}) / \mathrm{Sal}, \mathrm{F}(1,70)=91.46$, $p<0.0001 ; \mathrm{AF}(0.5 \mathrm{ml}) / \mathrm{Morph}$ vs. AF $(0.5 \mathrm{ml}) / \mathrm{Sal}, \mathrm{F}(1,70)=$ 13.71, $p<0.0005$; AF $(1.0 \mathrm{ml}) /$ Morph vs. AF $(1.0 \mathrm{ml}) / \mathrm{Sal}$, $\mathrm{F}(1,70)=17.48, p<0.0001$.

Morphine-injected rats fed $0.25,0.5$, or $1.0 \mathrm{ml}$ of amniotic fluid showed significantly greater increases from baseline (more analgesia) than did the morphine-injected rats fed the same volumes of beef bouillon: AF $(0.25 \mathrm{ml}) / \mathrm{Morph}$ vs. BB $(0.25 \mathrm{ml}) / \mathrm{Morph}, \mathrm{F}(1,140)=52.07, p<0.0001 ; \mathrm{AF}(0.5 \mathrm{ml}) /$ Morph vs. BB $(0.5 \mathrm{ml}) /$ Morph, $\mathrm{F}(1,140)=5.17, p<0.05 ; \mathrm{AF}$ $(1.0 \mathrm{ml}) /$ Morph vs. BB $(1.0 \mathrm{ml}) /$ Morph, $\mathrm{F}(1,140)=8.36$, $p<0.01$.

Morphine-injected rats fed $0.25,0.50$, and $1.0 \mathrm{ml}$ amniotic fluid showed greater increases in TFL than did morphineinjected rats fed either 0.125 or $2.0 \mathrm{ml}$ amniotic fluid $(p<0.05$, Newman-Keuls).

Morphine-injected rats receiving $0.25 \mathrm{ml}$ amniotic fluid had TFL increases that were significantly greater than those of all other groups $(p<0.01$, Newman-Keuls).

Morphine-injected rats receiving 0.125 or $2.0 \mathrm{ml}$ of amniotic fluid had mean percent changes in TFL that were not 


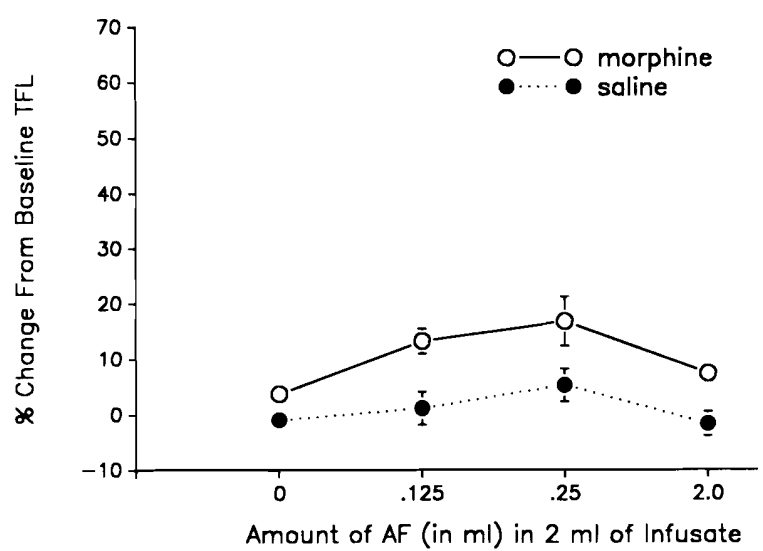

FIG. 2. Mean percent change from baseline tail-flick latency (TFL) in rats infused with various doses of amniotic fluid (AF) that were all diluted to $2 \mathrm{ml}$.

significantly different from those of bouillon-fed or salineinjected controls $(p>0.05)$.

Among the rats receiving no fluid during intubation, the group injected with saline had baseline TFLs of $3.20 \pm 0.11$ sec, and showed no change from baseline after saline injection $(-1.08 \pm 3.85 \mathrm{sec})$. The group injected with morphine but receiving no fluid had a baseline TFL of $3.32 \pm 0.11 \mathrm{sec}$, and showed increases after morphine treatment that were indistinguishable from those shown by the bouillon-fed morphine-injected controls $(+10.34 \pm 4.44 \%), F(5,39)=1.79$, $p>0.10$. Therefore, infusion of fluid, per se, had no effect on the analgesia produced by $3 \mathrm{mg} / \mathrm{kg}$ morphine sulfate.

Clearly, $0.25 \mathrm{ml}$ amniotic fluid is the optimal dose for enhancement of the analgesic effect of a $3 \mathrm{mg} / \mathrm{kg}$ injection of morphine sulfate, using our administration and testing timetable. The $0.5-\mathrm{ml}$ and $1.0-\mathrm{ml}$ doses of amniotic fluid showed POEF activity, but significantly less than the $0.25-\mathrm{ml}$ dose. The reason for the ineffectiveness of the $2.0-\mathrm{ml}$ dose of amniotic fluid is unclear. Since the present experiment did not employ a constant-volume method, we could not rule out an effect of volume, rather than of dose. A follow-up study was conducted to investigate that possibility.

\section{EXPERIMENT 2}

In Experiment 1, $0.25 \mathrm{ml}$ of infused amniotic fluid was found to produce a significant enhancement of the analgesia produced by an injection of morphine, whereas $2.0 \mathrm{ml}$ of infused amniotic fluid did not. In the present experiment we examined the POEF activity of four doses of amniotic fluid $(0,0.125,0.25$, and $2.0 \mathrm{ml})$ that were presented in a constant volume of infusate $(2.0 \mathrm{ml})$.

\section{METHOD}

Subjects

Thirty-two adult virgin Long-Evans female rats were used. The mean body weight for the group was $260.3 \pm 2.5 \mathrm{~g}$. They were housed and maintained the same as the rats in Experiment 1.

\section{Apparatus}

The apparatus used for assessment of TFL was the same as that used in Experiment 1.

\section{Procedure}

The procedural details of the present experiment were exactly the same as those described in Experiment 1, except that a) there were no beef bouillon control groups; b) the doses of amniotic fluid used were $0.00,0.125,0.25$, and 2.0 $\mathrm{ml}$; and c) the volume of infusate was always brought to 2.0 $\mathrm{ml}$ by the addition of $0.9 \%$ saline.

\section{RESULTS AND DISCUSSION}

The results of Experiment 2 are depicted in Fig. 2.

The baseline TFLs did not differ significantly among the groups. They ranged from $3.13 \pm 0.08 \mathrm{sec}$ in the AF $(0.25$ $\mathrm{ml}) / \mathrm{Sal}$ group, to $3.32 \pm 0.12 \mathrm{sec}$ in the AF $(0.25 \mathrm{ml}) / \mathrm{Morph}$ group, $\mathrm{F}(7,56)<1.0$

A two-way ANOVA, Drug (morphine, saline) $\times$ Dose of Fluid $(0.00,0.125,0.25,2.0 \mathrm{ml})$, indicated that there was not a significant interaction of Drug and Dose of Fluid, $F(3,28)<1.0$. Although the absolute differences were small, there was a statistically significant main effect of Drug, $\mathrm{F}(1,28)=21.04, p<0.0001$, in that morphine-treated rats had greater increases from baseline TFL (more analgesia) than did saline-treated rats. There was also a statistically significant main effect of Dose of Fluid, $\mathrm{F}(3,28)=6.00, p<0.005$; the rats infused with $0.25 \mathrm{ml}$ of amniotic fluid showed greater increases from baseline TFL than did those receiving 0.00 and $2.00 \mathrm{ml}(p<0.05$, Newman-Keuls).

As can be seen by comparing Fig. 2 with Fig. $1,0.25 \mathrm{ml}$ of amniotic fluid, when diluted to $2.0 \mathrm{ml}$, did not enhance the analgesia produced by $3 \mathrm{mg} / \mathrm{kg}$ morphine. Apparently, a large volume of fluid in the stomach interfered with the POEF effect.

\section{EXPERIMENT 3}

Ingestion of placenta has also been shown to enhance opiate-mediated analgesia (7). Pilot studies alluded to previously (7) suggested that although small amounts of ingested placenta enhanced analgesia, large amounts did not. In the present study we systematically examined the POEF activity of eight doses of placenta on the analgesia produced by a threshold dose $(3 \mathrm{mg} / \mathrm{kg})$ of morphine.

\section{METHOD}

\section{Subjects}

One hundred fifty-eight rats, with a mean body weight of $280 \pm 1.7 \mathrm{~g}$, and housed and maintained the same as those in Experiment 1, were used.

\section{Apparatus}

The TFL test apparatus and the restrainers were the same as those used in the previous experiments. Rats were tested in $20 \times 20 \times 18 \mathrm{~cm}$ wire mesh cages suspended $1.5 \mathrm{~cm}$ above a clean plastic surface (so that dropped meat could be retrieved by the subjects).

\section{Procedure}

The overall design of the experiment was a $2 \times 2 \times 8$ factorial: Drug (morphine, saline) $\times$ Meat (placenta, beef) $\times$ Dose of Meat $(0.063,0.125,0.25,0.50,1.0,2.0,3.5,5.0 \mathrm{~g})$. Each rat was assigned randomly to one of the 16 Dose $\times$ Meat groups, and was tested twice; once after a morphine injection, and once after a saline injection. The tests occurred two weeks apart, the order of the tests was balanced. 


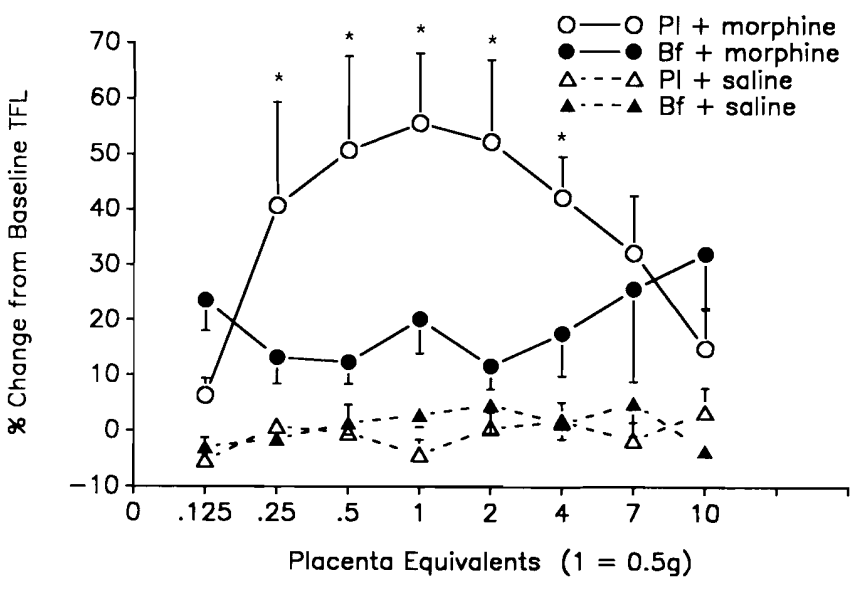

FIG. 3. Mean percent change from baseline tail-flick latency (TFL) in rats fed various doses of placenta $(\mathrm{Pl})$ or ground beef $(\mathrm{Bf})$, and injected with either morphine or saline. (Unfed rats receiving morphine in this paradigm show the same change in TFL as the Bf + morphine rats.) *Significantly greater than morphine controls and baseline.

Food and water were removed $2 \mathrm{hr}$ before testing. At the beginning of the test, a baseline TFL was taken and the injection of morphine or saline was administered. Fifteen minutes later, the meat was presented in a glass dish. After $30 \mathrm{~min}$, the postfeeding TFL was determined, and the remaining meat weighed.

Placenta was obtained as described in Experiment 1 , and frozen until needed. The control substance, ground sirloin beef, was obtained locally and treated just as the placenta was (7). The doses of placenta and beef given were based on the weight of a single placenta (approximately $0.5 \mathrm{~g}=1$ "placenta equivalent"). Therefore, the rats were presented with either $0.125,0.25,0.50,1.0,2.0,4.0,7.0$, or 10.0 placenta equivalents of meat. We wanted to test eight doses; since the amounts of meat became difficult to work with, and difficult for the rats to eat, we did not continue to double the doses beyond the 4.0 placenta equivalents.

Prior to the beginning of the experiment, all the rats were exposed to ground beef and placenta until they reliably ate about $1 \mathrm{~g}$ of placenta/beef $\mathrm{mix}$ in $15 \mathrm{~min}$.

The meat was weighed prior to and after the 30 -min presentation period. Data were included only from those rats that ate all the meat presented, or ate an amount that fell within one standard deviation of the mean weight of the placenta presented to that dose group. In this way, the criterion for inclusion was based on placenta equivalents for both meat groups.

To test the effects of the saline and morphine injections alone, five additional rats were treated identically to the rest but received no meat during the feeding period.

As in the previous experiments, the experimenter testing TFL was blind to the condition of the rat.

\section{RESULTS AND DISCUSSION}

The results of Experiment 3 are depicted in Fig. 3 .

The proportion of meat presented that was eaten by the subjects did not differ among the groups, since virtually all the rats that did not finish all the meat failed to eat enough to reach the criterion for inclusion. Thirty rats were excluded, resulting in an $\mathrm{N}$ of 128 . The overall mean of the percent of

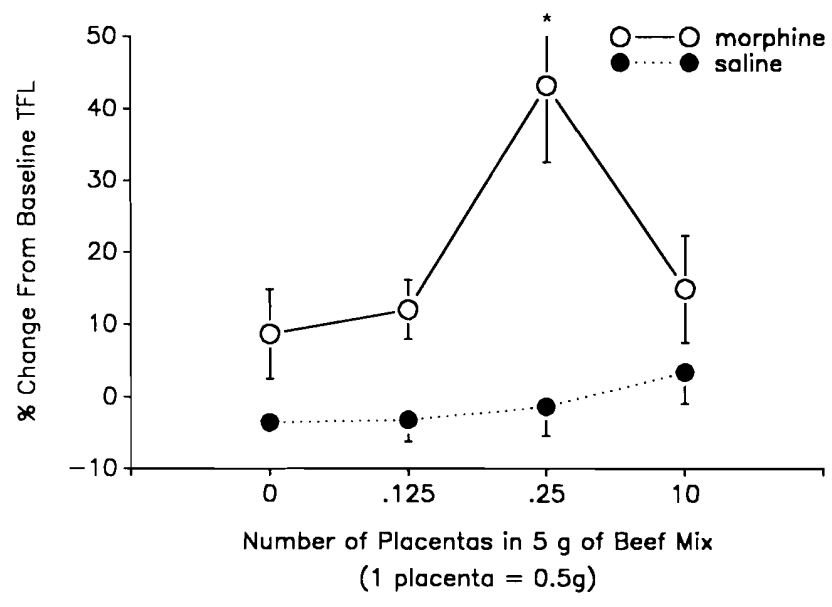

FIG. 4. Mean percent change from baseline tail-flick latency (TFL) in rats fed various doses of placenta in $5 \mathrm{~g}$ of beef mix. ${ }^{*}$ Significantly greater than saline controls and baseline.

presented meat that was eaten, of the 128 included rats, was $99.86 \pm 0.0008 \%$. The overall mean of the percent of meat eaten, of the 30 rats excluded from the study, was $69.15 \pm 0.048 \%$. There was no significant correlation between the amount eaten and the percent change from baseline TFL response within any group.

The baseline TFLs did not differ significantly among the groups. They ranged from $3.12 \pm 0.08 \mathrm{sec}$ in the morphineinjected rats receiving $0.063 \mathrm{~g}$ placenta (PLA) to $3.49 \pm 0.10$ in the saline-injected rats receiving $0.25 \mathrm{~g}$ beef $(\mathrm{Bf})$, $\mathrm{F}(31,224)<1.0$.

A three-way ANOVA (Drug $\times$ Meat $\times$ Dose of Meat) revealed a significant Drug $\times$ Meat $\times$ Dose interaction, $\mathrm{F}(7,112)=2.69, p<0.02$. Subsequent two-way ANOVAs probing the various effects revealed a significant Drug $\times$ Dose of Meat interaction in placenta-fed rats, $F(7,112)=2.55$, $p<0.02$; a significant Drug $\times$ Meat interaction in rats fed either $0.25 \mathrm{~g}, 0.50 \mathrm{~g}$, or $1.0 \mathrm{~g}, \mathrm{~F}(1,112)=6.39, p<0.02$, $\mathrm{F}(1,112)=7.15, p<0.01$, and $\mathrm{F}(1,112)=7.93, p<0.01$, respectively; and a significant Meat $\times$ Dose of Meat interaction in morphine-injected rats, $\mathrm{F}(7,224)=4.53, p<0.01$. More detailed analyses were then conducted using ANOVAs and Newman-Keuls tests.

Among morphine-injected rats fed placenta, there was a significant effect of dose, $F(7,224)=5.16, p<0.01$, in that those receiving 0.5 or $1.0 \mathrm{~g}$ showed significantly greater increases in TFL (more analgesia) than did those fed 0.063 or 5 $\mathrm{g}$; those fed $0.125,0.25$ or $2.0 \mathrm{~g}$ showed significantly greater increases than those receiving $0.063 \mathrm{~g}$ (Newman-Keuls, $p<0.05$ ).

Morphine-treated rats fed $0.125,0.25,0.50,1.0$ or $2.0 \mathrm{~g}$ of placenta showed significantly greater increases in TFL than those fed equivalent amounts of beef: PLA $(0.125 \mathrm{~g}) / \mathrm{Morph}$ vs. Bf $(0.125 \mathrm{~g}) / \mathrm{Morph}, \mathrm{F}(1,224)=6.00, p<0.05 ;$ PLA $(0.25$ g)/Morph vs. Bf $(0.25 \mathrm{~g}) / \mathrm{Morph}, \mathrm{F}(1,224)=11.77, p<0.01$; PLA $(0.50 \mathrm{~g}) / \mathrm{Morph}$ vs. Bf $(0.50 \mathrm{~g}) / \mathrm{Morph}, \mathrm{F}(1,224)=10.02$, $p<0.01 ;$ PLA $(1.0 \mathrm{~g}) / \mathrm{Morph}$ vs. Bf $(1.0 \mathrm{~g}) / \mathrm{Morph}$, $\mathrm{F}(1,224)=13.19, p<0.01 ;$ PLA $(2.0 \mathrm{~g}) / \mathrm{Morph}$ vs. Bf $(2.0$ g)/Morph, $\mathrm{F}(1,224)=4.81, p<0.05$.

Among groups receiving beef, there were no significant differences due to dose, $F(7,224)<1.0$.

Rats receiving saline injections but ingesting no meat had 
baseline TFLs of $3.2 \pm 0.11 \mathrm{sec}$, and showed no change from baseline after saline injection $(-1.59 \pm 5.10 \%)$. The group receiving morphine injections but ingesting no meat had a baseline of $3.15 \pm 0.16$, and showed percent increases from baseline TFL after morphine treatment that were indistinguishable from those of the beef-fed morphine-injected controls $(+20.65 \pm 17.55 \%), F(8,60)<1.0$. Therefore, ingestion of meat, per se, had no effect on the analgesia produced by 3 $\mathrm{mg} / \mathrm{kg}$ morphine sulfate.

Placenta, in doses of $0.125,0.25,0.50,1.0$, or $2.0 \mathrm{~g}$, significantly enhanced the analgesia produced by a $3 \mathrm{mg} / \mathrm{kg}$ injection of morphine. These weights correspond to $1 / 4,1 / 2,1,2$, or 4 placentas. Experiment 3 did not use a constant volume or weight procedure. Therefore, a follow-up study was conducted in which effective and ineffective doses of placenta were presented in a constant weight of meat.

\section{EXPERIMENT 4}

To examine the role of the amount of material ingested on the POEF activity of placenta, an effective dose $(0.25$ placentas) and three ineffective doses $(0.00,0.125$, and 10.0 placentas) were each presented in enough ground beef to bring the weight of the material to $5.0 \mathrm{~g}$ (10 placentaequivalents).

\section{METHOD}

\section{Subjects}

Forty adult virgin Long-Evans female rats, with a mean body weight of $278 \pm 3.2 \mathrm{~g}$, and housed and maintained the same as the rats in the previous three experiments, were used.

\section{Apparatus}

The TFL testing apparatus and restrainers were the same as those used in the previous three experiments.

\section{Procedure}

The procedural details were the same as those of Experiment 3, except that each rat was presented with $5.0 \mathrm{~g}$ of material, regardless of the dose of placenta.

The doses of placenta tested were $0.00,0.063,0.125$, and $5.0 \mathrm{~g}$. The data for the $0.0 \mathrm{~g}$ and the $5.0 \mathrm{~g}$ groups were those collected in Experiment 3.

After the initial experience with meat, each rat in the $0.00-\mathrm{g}, 0.063-\mathrm{g}, 0.125 \mathrm{-g}$, and $5.0-\mathrm{g}$ groups was fed meat each day for one to three days before each experiment session, to insure that it would eat $5.0 \mathrm{~g}$ of meat presented during the experiment.

\section{RESULTS}

The results of Experiment 4 are depicted in Fig. 4 .

All the rats included in the study ate all $5 \mathrm{~g}$ of the meat they were offered.

The mean baseline TFLs did not differ significantly among the groups, and ranged from $3.20 \pm 0.09 \mathrm{sec}$ in the PLA (0.125 g)/Morph group, to $3.41 \pm 0.12 \mathrm{sec}$ in the PLA $(5.0 \mathrm{~g}) / \mathrm{Sal}$ group, $\mathrm{F}(7,56)<1.0$.

A two-way ANOVA, Drug (morphine, saline) $\times$ Amount of Placenta $(0.00,0.063,0.125,5 \mathrm{~g})$, revealed a significant interaction of Drug and Amount of Placenta, $F(3,28)=4.45$, $p<0.025$. Further probes of the effect were conducted using ANOVAs and Newman-Keuls tests.
Morphine-injected rats receiving $0.125 \mathrm{~g}$ placenta showed significantly greater increases in TFL than did their salineinjected controls, PLA (0.125 g)/Morph vs. PLA $(0.125$ g)/Sal, $\mathrm{F}(1,28)=32.21, p<0.0001$.

The morphine-injected rats receiving $0.125 \mathrm{~g}$ placenta showed significantly greater increases in TFL than did the morphine-injected rats receiving other amounts of placenta, $F(3,56)=7.26, p<0.01$ (Newman-Keuls comparison, $p<0.05$ ).

In contrast to the findings of Experiment 2, the absolute size of the dose of material ingested did not affect POEF activity. A dose of placenta found to be effective in Experiment $3,1 / 4$ of a placenta $(0.125 \mathrm{~g})$, was effective when diluted to $5.0 \mathrm{~g}$ with ground beef. In Experiment 2, a dose of amniotic fluid found to be effective in Experiment 1, $0.25 \mathrm{ml}$, did not show POEF activity when diluted with beef bouillon to a 2-ml infusion.

\section{GENERAL DISCUSSION}

Both amniotic fluid and placenta contain POEF activity. Presumably, parturient female mammals benefit from ingesting amniotic fluid immediately prior to delivery by experiencing an enhancement of endorphin-mediated analgesia. (Such an endorphin-mediated analgesia, "analgesia of pregnancy," was described elsewhere $(2,5)$, and has been observed in our laboratory.) Subsequently, ingestion of the placenta in the period after the delivery of the infant may afford an additional short-term enhancement of endogenous-opioid-mediated analgesia.

Experiment 1 revealed that the optimal dose of amniotic fluid for the enhancement of analgesia produced by $3 \mathrm{mg} / \mathrm{kg}$ morphine was $0.25 \mathrm{ml}$. Experiment 3 revealed that the optimal dose of placenta for the enhancement of the same level of morphine analgesia is in the range of 0.5 to 2.0 placentas $(0.25 \mathrm{~g}$ to $1.0 \mathrm{~g})$. It is important to note that these are the approximate amounts present at the delivery of each rat pup. Also, large amounts of placenta and amniotic fluid presented for brief periods is somewhat artificial, since pups are delivered one at a time, at 20- to 45-min intervals.

The finding in Experiment 3 of a down-slope to the placenta dose-response curve, and the finding in these and previous experiments that placenta ingestion or amniotic fluid ingestion alone does not produce analgesia $(6,7)$, support the idea that POEF is not an opioid, nor does it simply increase the output of endogenous opioids.

It is not clear why an effective dose of amniotic fluid $(0.25$ $\mathrm{ml}$ ) should lose its POEF activity when diluted to a $2.0 \mathrm{ml}$. A comparable loss does not occur when an effective dose of placenta $(0.125 \mathrm{~g})$ is diluted to $5.0 \mathrm{~g}$. The answer may relate to the effect of different volumes of liquid on gastric emptying time. If $2.0 \mathrm{ml}$ produces very rapid gastric emptying (9), and POEF activity involves gastric receptors (1), POEF, whether active as ingested, or produced or activated during digestion, may not remain in the stomach long enough to have an effect. Indirect evidence for the involvement of gastric receptors has been obtained from pilot work in our laboratory that shows that although orogastrically-infused amniotic fluid shows POEF activity (6), intraperitoneally- or subcutaneously-injected amniotic fluid does not.

When the degree of stomach distention is controlled for, large doses of placenta do not show the enhancement of morphine-mediated analgesia seen with ingestion of small to moderate amounts. Several explanations can be put forth for this. a) When abnormally large amounts of placenta are eaten in a short time, some POEF antagonist present in placenta in 
small amounts may accumulate in a sufficient amount to compensate for or cancel the effect of POEF. Or b) two types of receptors for POEF may be present, one with a high affinity that produces opioid enhancement, and one with a lower affinity that produces opioid inhibition. This arrangement could lead to an apparently biphasic agonist/antagonist response. In either case, one would also have expected to see a reversal of POEF activity with large doses of amniotic fluid, as well as large doses of placenta, but Experiment 2 revealed a confounded effect of volume: large doses of amniotic fluid reversed POEF activity because of the volume of the dose. However, it is still possible that hidden behind the inhibitory effect of the large volume of fluid is the downward slope of the dose-response curve. Pilot data in our laboratory support this idea in that concentrated amniotic fluid, infused in small volumes, shows reduced, or even completely negated, POEF activity.

\section{ACKNOWLEDGEMENTS}

This research was supported primarily by NSF Grant BNS8601818 awarded to M.B.K. We thank Seymour Axelrod for his helpful comments on an earlier version of this paper.

\section{REFERENCES}

1. Andrews, P. L. R. Vagal afferent innervation of the gastrointestinal tract. Prog. Brain Res. 67:65-86; 1986.

2. Baron, S. A.; Gintzler, A. R. Pregnancy-induced analgesia: effects of adrenalectomy and glucocorticoid replacement. Brain Res. 321:341-346; 1984.

3. Bolles, R. C.; Fanselow, M. S. Endorphins and behavior. Annu. Rev. Psychol. 33:87-101; 1982.

4. D'Amour, F. E.; Smith, D. L. A method for determining loss of pain sensation. J. Pharmacol. Exp. Ther. 72:74-79; 1941.

5. Gintzler, A. R. Endorphin-mediated increases in pain thresholds during pregnancy. Science 210:193-195; 1980.

6. Kristal, M. B.; Thompson, A. C.; Abbott, P. Ingestion of amniotic fluid enhances opiate analgesia in rats. Physiol. Behav. 38:809-815; 1986

7. Kristal, M. B.; Thompson, A. C.; Grishkat, H. L. Placenta ingestion enhances opiate analgesia in rats. Physiol. Behav. $35: 481-486 ; 1985$
8. Kristal, M. B.; Thompson, A. C.; Heller, S. B.; Komisaruk, B. $R$. Placenta ingestion enhances analgesia produced by vagi$\mathrm{nal} /$ cervical stimulation in rats. Physiol. Behav. 36:1017-1020; 1986.

9. McHugh, P. R. The control of gastric emptying. J. Auton. Nerv. Syst. 9:221-231; 1983.

10. Taber, R. I. Predictive value of analgesic assays in mice and rats. In: Braude, M. C.; Harris, L. S.; May, E. L.; Smith, J. P.; Villarreal, J. E., eds. Advances in biochemical pharmacology. vol. 8. Narcotic antagonists. New York: Raven Press; 1974.

11. Yoburn, B. C.; Cohen, A.; Umans, J. G.; Ling, G. S. F.; Inturrisi, C. E. The graded and quantal nature of opioid analgesia in the rat tail-flick assay. Brain Res. 331:327-336; 1985.

12. Yoburn, B. C.; Morales, R.; Kelly, D. D.; Inturrisi, C. E. Constraints on the tailflick assay: morphine analgesia and tolerance are dependent upon locus of tail stimulation. Life Sci. 34:1755$1762 ; 1984$. 